\title{
Between control and complexity: opportunities and challenges for marine mesocosms
}

Raphael D Sagarin ${ }^{1}$, John Adams ${ }^{1}$, Carol A Blanchette ${ }^{2}$, Richard C Brusca ${ }^{3}$, Jon Chorover ${ }^{4}$, Julia E Cole ${ }^{5}$, Fiorenza Micheli ${ }^{6}$, Adrian Munguia-Vega ${ }^{7}$, Chelsea M Rochman ${ }^{8}$, Kevin Bonine ${ }^{1,3}$, Joost van Haren ${ }^{1,9}$, and Peter A Troch ${ }^{10 *}$

Marine ecologists have a wide array of tools with which to study complex and dynamic systems, but there are cases where neither simple, highly controlled experiments nor largely uncontrolled, more complex field observations provide adequate inferential power. In such cases, mesocosm studies in marine systems may help bridge the gap. Mesocosm studies can facilitate research ranging from basic biology to multifactorial ecosystem studies that involve observation, perturbation, validation, calibration, long-term studies, and testing of new technologies. Although scale, closed boundaries, biodiversity levels, and replication can impose challenges on mesocosm research, these parameters can also help to define research opportunities that are uniquely suited to such controlled environments. Finally, we provide examples of successful marine mesocosm research and discuss opportunities for future work.

Front Ecol Environ 2016; 14(7): 389-396, doi:10.1002/fee.1313

$M^{\text {any }}$ any outstanding questions in marine ecology including those related to basic life history, carbon cycling, population monitoring, fate and toxicity of contaminants, mechanisms controlling biodiversity, and studies of global change - could benefit from controlled experimentation at relatively large scales. Capacity for studying ecological systems accelerated in the late 20th century with the extensive adoption of manipulative experimental methodologies. One productive response was to perform similar experiments at multiple locations along

\section{In a nutshell:}

- Mesocosms are enclosed environments that combine the control of laboratory experiments with some of the complexity of natural ecosystems

- Although frequently used to investigate terrestrial and freshwater ecosystems, mesocosms are underutilized in marine ecology due to challenges of scale, openness, complexity, and replication

- By allowing researchers to address critical questions in marine ecology, mesocosms can help bridge the gap between small-scale controlled experiments and field observations

- As the largest marine mesocosm ever built, the University of Arizona's Biosphere 2 Ocean mesocosm overcomes some of the challenges associated with smaller systems

\footnotetext{
${ }^{1}$ Biosphere 2, University of Arizona, Tucson, AZ; ${ }^{2}$ Marine Science Institute, University of California-Santa Barbara, Santa Barbara, CA; ${ }^{3}$ Department of Ecology 83 Evolutionary Biology, University of Arizona, Tucson, AZ; ${ }^{4}$ Department of Soil, Water and Environmental Science, University of Arizona, Tucson, AZ; ${ }^{5}$ Department of Geosciences and Department of Atmospheric Sciences, University of Arizona, Tucson, AZ; continued on p 396
}

a biogeographic gradient or in similar ecosystems in different biogeographic regions, to improve understanding of large-scale mechanisms (Menge et al. 1994, 2002; Vitousek 2004; Paine 2010). Because not all systems are conducive to this comparative experimental approach, we have seen greater usage and acceptance of observation-based studies, which do not rely on controlled manipulation of variables (Sagarin and Pauchard 2012). Advances in technologies pertinent across scales of biological complexity - from genomics to remote sensing - have amplified the power of observational studies to infer mechanisms underlying ecological phenomena (Pickett et al. 2007).

Highly controlled experimental manipulations and open-ended field observations each provide important insights in marine research, but integrating the results from these disparate approaches can be challenging due to the disparity between their spatial and temporal scales. The outcome of a small-scale controlled manipulation may not be consistent with field observations of an unconstrained system, and identifying the reasons why this is so can be beyond the scope of either approach. Research questions arise that cannot be addressed in either the laboratory or the complex and largely uncontrollable field arena (Tyre et al. 2003; Biber 2011; Witze 2015). The elucidation of scale- and feedback-dependent processes will ultimately require both fine environmental control and high-resolution observations. This becomes more important as environmental and ecological changes intensify in response to human activity. Understanding, predicting, and managing such change may require knowledge that integrates single-variable manipulative techniques with the complexity of the natural world, where it is nearly impossible to tease apart the many 
variables. This can be particularly difficult today, with the addition of many human-induced stressors such as the introduction of non-native species, overfishing, climate change, and pollution.

A largely under-explored space in marine ecological research that can address some of these gaps is the mesocosm, a device that features some of the control of a laboratory (or experimental plot) and some of the complexity and scale of the natural world (eg Wilson et al. 2015). In an ideal mesocosm, processes can be controlled and measured across spatial scales, and specific control components can be engaged or disengaged.

Here we discuss some of the opportunities and challenges of marine mesocosm research. Marine ecosystems are large and fourdimensional in scale, and their openness and continuity influence the way in which ecological systems function. As a consequence, processes in marine systems need to be explicitly considered when designing marine mesocosm experiments. For example, nutrients and organisms are retained,

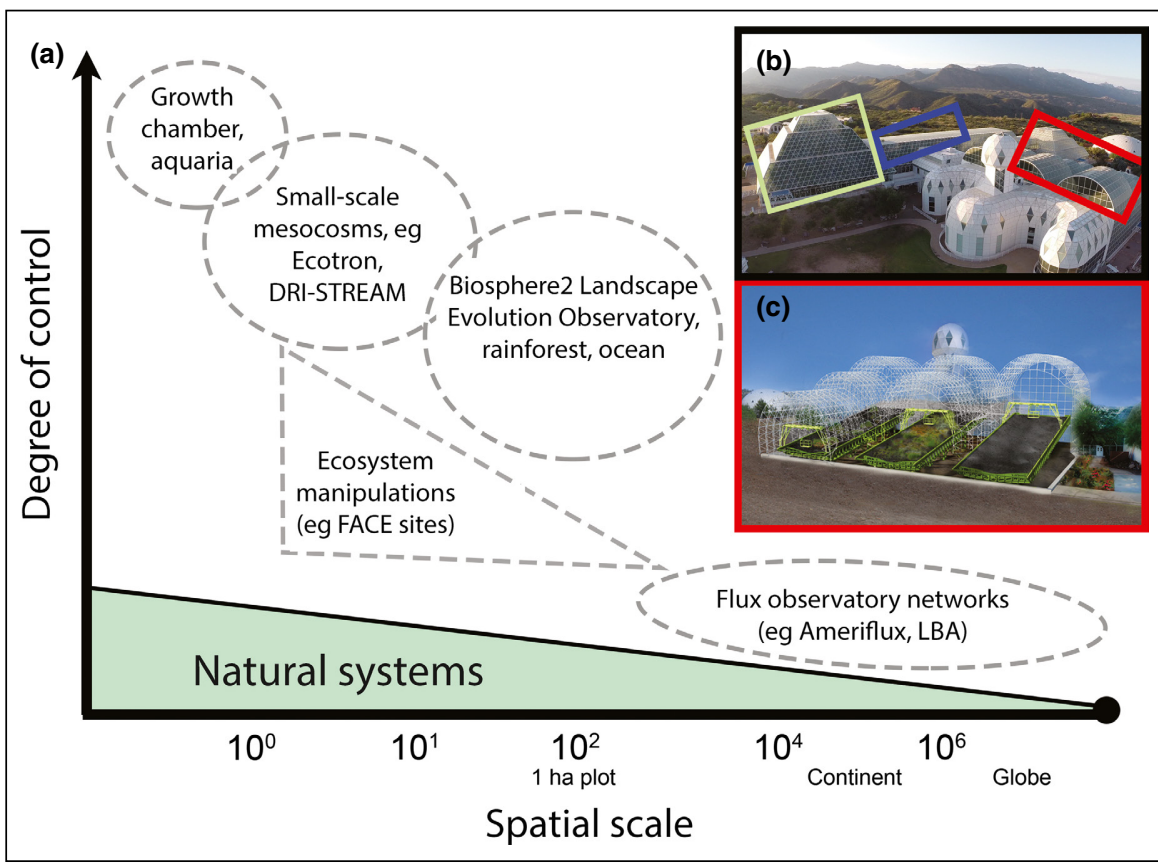

Figure 1. (a) Relative controllability of various sample mesocosms along a compressed size scale. (b) Photograph of Biosphere 2, with approximate locations of the rainforest (light green rectangle), ocean (blue rectangle), and Landscape Evolution Observatory (LEO; red rectangle) mesocosms. (c) Schematic of the LEO. Mesocosm names and websites: Marine Ecosystems Research Laboratory (MERL; www.gso.uri.edu/merl/ merl.html), Ecotron (www.ecotron.cnrs.fr), Drought Impacts on Stream Ecosystem Functioning (DRI-STREAM; http://bit.ly/1S5ViYJ). Flux observatory network names and websites: Ameriflux (http://ameriflux.lbl.gov), Fluxnet (www.fluxdata.org). FACE = Free-Air Carbon Dioxide Enrichment LBA = Large-scale Biosphere-Atmosphere Experiment in Amazonia. diffused, transported, or aggregated by ocean currents that are spatially and temporally variable due to the interaction of multiple physical processes (eg tides, waves, winds, topography, bathymetry) (Denny 1993). In addition, many marine organisms (eg invertebrates and fish) have complex life cycles involving a pelagic larval stage that evolved to match the variable physical environment (Strathmann 1990). Accordingly, while the use of mesocosms in marine ecological research offers unique opportunities, it also comes with challenges. As with other approaches, mesocosm research can be difficult and costly and has limitations in utility and scope. However, the size and control available in such studies can play a critical role in bridging across scales to link laboratory findings with real-world observations.

\section{What exactly is a mesocosm?}

In simplest terms, a mesocosm is an experimental system - with known boundary conditions - that includes both controllability and complexity. A mesocosm typically does not feature the degree of controllability afforded by a laboratory setting, nor is it a perfect replica of a natural system. Rather, it should be viewed as a tool to answer questions that cannot be addressed fully under highly controlled simplistic conditions or complex and largely uncontrolled natural conditions. The areal extent of mesocosms may range from chambers of less than a square meter, to indoor ecosystem experiments close to a hectare, to networked sites spanning continents (Figure 1).

The University of Arizona's Landscape Evolution Observatory (LEO) at Biosphere 2 (B2) is an example of a terrestrial mesocosm used to answer big-picture ecological questions. The LEO is a set of three replicate $340-\mathrm{m}^{2}$ hillslope environments (Figure 1) designed to observe and manipulate the co-evolution of physical, chemical, and biological properties of watersheds and their effects on biogeochemical cycles (Pangle et al. 2015). The designers of the LEO created a unique opportunity to develop a large-scale mesocosm experiment from the ground up (Huxman et al. 2009). Early experiments at this facility have allowed direct observation of water transit time distributions (impossible in real systems), and the discovery of landscape-scale limiting processes on chemical weathering of basalt substrates. Successful mesocosm projects such as this demonstrate the feasibility of mesocosms and quell skepticism about their value. 


\section{Marine mesocosm opportunities}

Marine mesocosms provide opportunities for diverse research objectives:

(1) Observation. Many basic life-history questions regarding marine organisms - such as growth rates, larval longevity and behavior - may be especially suitable for mesocosm experiments. Biochemical cycling may be logistically more feasible to observe in a mesocosm, as studies of carbon cycling in the B2 Ocean revealed (Langdon et al. 2003). Moreover, certain applied observations - such as mechanisms that drive the physical and chemical fate of plastic debris (Teuten et al. 2009; Law et al. 2010) in marine environments - can be made in a mesocosm more effectively than in a small-scale laboratory experiment or the open ocean.

(2) Perturbation. The ability to perturb both the ecology and biogeochemistry in a marine mesocosm is a key asset because it is much more difficult to do so in a laboratory or field experiment (Langdon et al. 2000, 2003). Because these perturbations can be conducted in parallel, sequentially, or in repeated pulses, marine mesocosms offer the chance to decouple the roles of competing variables of interest, which is usually impossible in the field. The feedbacks among carbon chemistry, individual species, and marine ecosystems, for example, have been identified as a key gap in acidification science (Pfister et al. 2014) and could be addressed in a mesocosm.

(3) Validation. A marine mesocosm can complement model validations that use historical data by providing instrumental and experimental data under a range of scenarios. Mesocosms may also validate results from small-scale manipulations that are difficult to confirm from large-scale field observations (eg because the system is too complex to tease apart variables). For instance, parallel evolutionary forces (eg immigration, genetic drift) seem to affect species and genetic diversity declines over short timescales following disturbance according to modeling and field studies (Vellend 2005; Cleary et al. 2006). However, theory has lagged behind regarding when one can be used to predict the other, in part due to high environmental heterogeneity that may be controlled for in a mesocosm.

(4) Calibration. A compelling use of mesocosms is to calibrate response curves between variables to make sense of field observations. One important application of this may lie in quantifying the relationship among genetic and other measures of biodiversity. Although many investigators now use environmental DNA (eDNA) and bioinformatics to measure diversity in the wild (eg Thomsen et al. 2012), many questions remain unanswered regarding the sensitivity of the technique when multiple species vary in space and time and how to translate presence/absence data into quantitative estimates (Foote et al. 2012; Kelly et al. 2014).

(5) Long-term studies. Observations are unified and enhanced with long-term observation and monitoring. In particular, non-linear response pathways may emerge only when studies are extended over time (Osmond et al. 2004), yielding different predictions and parameterization of system models than short-term studies. In one study, long-term mesocosm experiments measuring the recovery of a system after exposure to toxicants reveal that although these vanish rapidly from the water column, small concentrations of pollutants linger for years in the benthic environment (Oviatt et al. 1984).

(6) Technology test bed. Development of environmental sensing and exploration technologies faces similar constraints as described above for basic ecological research (Wynn et al. 2014). Conditions need to be complex, but controllable. A marine mesocosm with salt water, complex topography, variably controlled water quality and clarity, complex soundscapes, and living organisms - which may interfere with, biofoul, or actively avoid the technology - provides opportunities for developers to study real-world exposures with much lower risk of losing a valuable prototype.

\section{Particular challenges of an ocean mesocosm}

The most obvious restriction for an ocean mesocosm is scale. Many biological oceanographic features occur across scales that are orders of magnitude larger than any conceivable ocean mesocosm (Mann and Lazier 2006). These features - such as current patterns, larval transport, and nutrient cycling - have real and identifiable consequences at the local scale and cannot be ignored when considering smaller-scale phenomena (eg Selkoe et al. 2015). It is critical to deliberately constrain the type of marine environment that is being simulated in the mesocosm and focus on questions directly relevant to that environment. For example, while open-ocean dynamics may be difficult to scale down, nearshore dynamics that occur (in part) on scales of meters to tens of meters, such as nutrient exchange across the land-sea interface, may be possible to replicate in a mesocosm (Álvarez-Romero et al. 2011).

A second major challenge for an ocean mesocosm is its closed boundaries relative to the ocean. Wave forces, 


\section{Panel 1. The history and future of the Biosphere 2 Ocean}

The Biosphere 2 (B2) Ocean is a rare example of a large marine mesocosm with research as its primary rationale. The ocean is a $35-\mathrm{m} \times 20-\mathrm{m}$ rectangle, with a complex bathymetry featuring a 7-m depth zone that slopes upward to a shallow lagoon and fringing reef with a sandy beach (Figure 2). The ocean volume is approximately $2650 \mathrm{~m}^{3}$ and its surface area is $711 \mathrm{~m}^{2}$ (Atkinson et al. 1999). Originally, the B2 Ocean biome was created as an integral part of a sealed, self-supporting multihabitat environment that also included a rainforest, savanna, marsh, desert, and intensive agricultural area, and supported eight human inhabitants for a two-year mission (Marino and Odum 1999; Poynter 2006; Reider 2009).

After the conclusion of the original sealed "manned missions" of B2, Columbia University acquired the facility in 1996 for global change research and teaching. Columbia unsealed and separated the biomes to enable greater

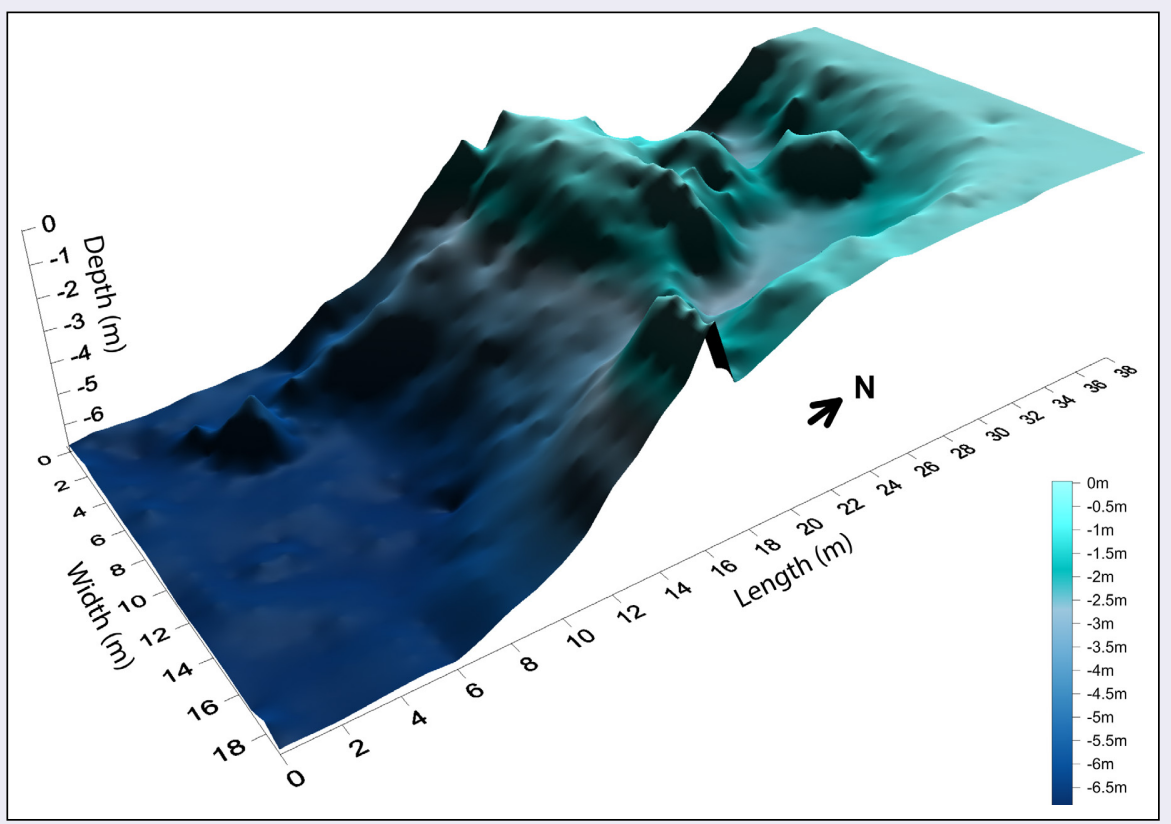

Figure 2. Current bathymetry of the Biosphere 2 Ocean.

control in any given area. A body of marine research on biogeochemistry and ocean-atmosphere gas exchange was developed during this time (eg Atkinson et al. 1999; Sweeney 1999; Falter et al. 200I), including some of the first long-term experiments on the effects of ocean acidification on coral and ecosystem calcification and on community metabolism (Langdon et al. 2000, 2003; Marubini et al. 200I).

Columbia's departure from B2 in 2003 resulted in a period of benign neglect that particularly affected the ocean biome.
Currently, the ocean is very low in diversity and population density of animals - with no live corals and an estimated 90-95\% algal cover on hard surfaces - as compared to the Biospherian and Columbia eras. This situation provides an opportunity to re-envision the B2 Ocean and move away from the energy- and maintenance-intensive coral reef model.

Our vision for the B2 Ocean, moving forward, emphasizes the importance of understanding "Desert Seas". Worldwide, a substantial fraction of the coastal ocean abuts arid or semi-arid lands
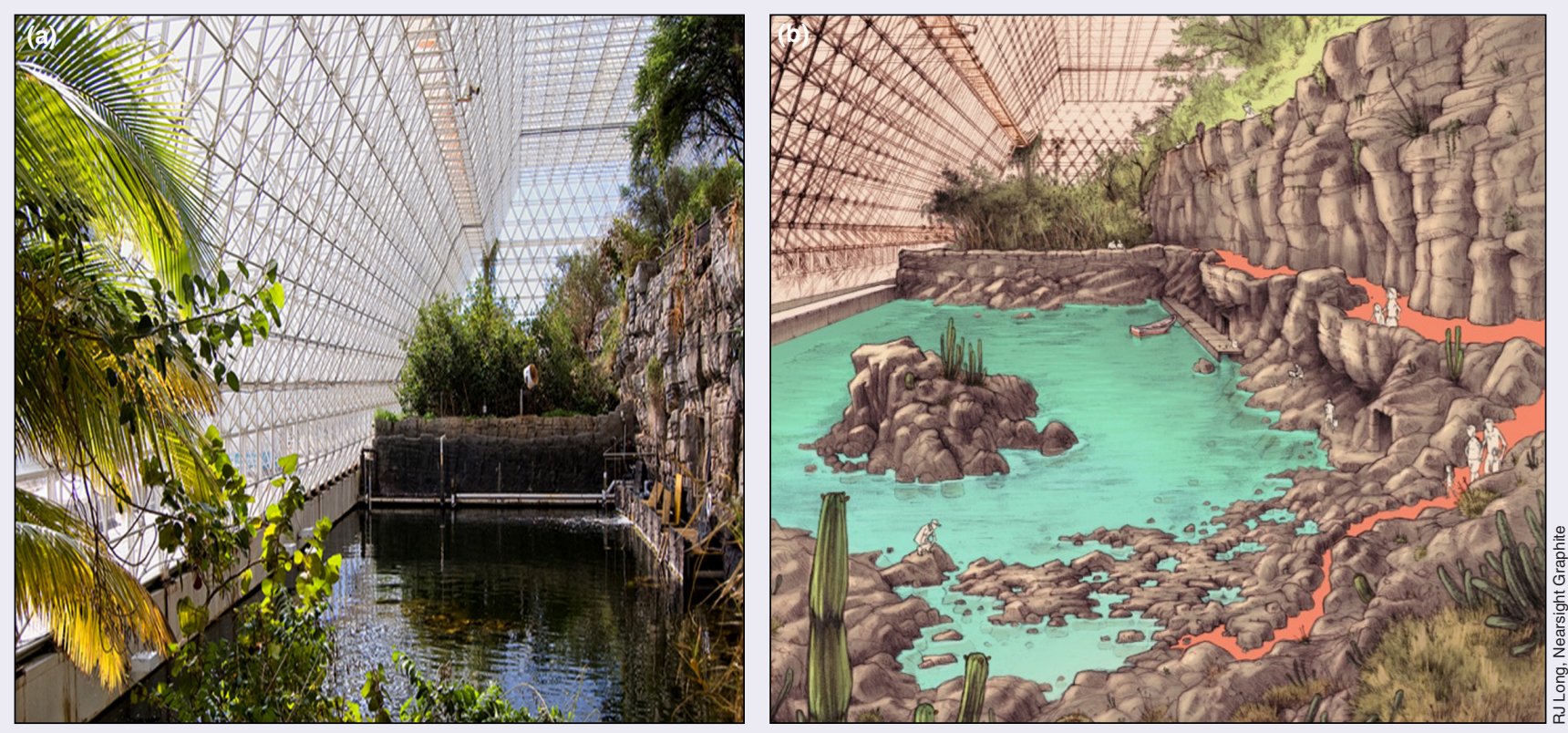

Figure 3. (a) Current Biosphere 2 Ocean mesocosm. Visitor viewing is from the top of the rock wall on the right. (b) First draft of possible transformation to a Gulf of California model mesocosm; orange pathways indicate new access/viewing points for visitors. 
in the subtropics. These oceans support diverse marine ecosystems along with local economies, cultures, and food systems. The scientific goals of the project will address biological diversity in an era of anthropogenic change. This is a globally relevant vision that ties into local expertise in semi-arid ecosystems and the B2's nearest marine environment, the Gulf of California. Research on environmental change and biodiversity will provide a pedagogical link between global processes and the changes occurring in the Gulf (Sagarin et al. 2008; Brusca 2010).

Nonetheless, the original B2 Ocean was not built specifically for manipulative research projects. The sandy beach, for example, erodes quickly when wave action is increased in the ocean and thus has limited research into biophysical processes. Accordingly, design plans could include physical modifications of the mesocosm, such as transforming the beach into a rocky shoreline with tidal pools, that would provide the public with a sense of the high-diversity Gulf of California environments and scientists with more robust platforms to conduct research (Figure 3).

Ultimately, the goal of the ocean transformation project is to provide a platform for marine research that can be used by scientists or technology developers on a subscription or userfee basis, similar to how many telescope facilities and marine biology laboratories operate today. To make this platform more useful, a series of design charrettes - beginning in 2013 - have brought marine biologists, conservation biologists, ecologists, aquarists, and exhibit designers to B2 to conceptualize the research, design, and outreach priorities for the project. A challenge in this design process, and for all marine mesocosms, is finding ways to combine a strong and adaptable platform for marine research with a compelling space for public science outreach. currents, ocean-atmosphere interactions, and direct or indirect biological transport provide numerous ways in which nutrients, pollutants, and biological organisms can enter, exit, and organize a marine system (Siegel et al. 2003; Cowen and Sponaugle 2009). The physical walls around the mesocosm and the manner in which seawater and organisms are introduced affect this kind of transport. This produces both a challenge and opportunity. The challenge is to design a system and experimental design in which inputs and outputs to the system (as well as the intervening dynamics) are carefully tracked. Extensive (spatially dense), real-time environmental sensors as well as basic population monitoring are therefore both necessary and feasible for marine mesocosms. Introduction and removal of species will usually be deliberate, although unintentional introductions are still inevitable, particularly in the microbiome. The ability to track these flows within mesocosms - enhanced relative to field studies by the mesocosm structure and by new sensor and genomic technologies - presents a clear opportunity to address questions that are logistically difficult or impossible to answer in the field.

A third challenge is maintaining an appropriate level of biodiversity, which is related to both issues of scale and physical boundaries in marine mesocosms. By not capturing the large-scale dynamics of currents and larval pools that drift and swim within, mesocosms can only approximate the major source of diversity input (Watson et al. 2011; Treml et al. 2015). Additionally, organisms that might normally escape predation may literally have nowhere to hide. Design considerations - such as creating complex topography and habitat, large open-water zones, and tidal systems (that might limit the mobility of certain predators or herbivores) - can create refugia for species, and may also be used to test theories about the relationship between habitat complexity and diversity (Kostylev et al. 2005). Species composition can be manipulated to avoid incompatibilities and to include symbiotic partners and desirable habitat "engineers". Thus, the ideal suite of species for a mesocosm to function may be different than any current or past assemblage of species in a real-world ecosystem.

A fourth challenge is replication. Unlike treatments conducted in 20-gallon aquarium tanks, it is logistically difficult to replicate large-scale ocean mesocosms. As we move to larger scales of space and increased complexity, true replication becomes exceedingly difficult. At B2, to address replication concerns, the LEO project created three identical hillslope platforms arranged side by side within an enclosed $5000-\mathrm{m}^{2}$ section. Yet even in this highly controlled structure, there will be slight differences due to ambient light and temperature between the westernmost, easternmost, and central bays. The difficulty of balancing replication with achieving reasonable inference in complex systems is one that both field and laboratory ecologists have recognized and debated for some time (eg Schindler 1998; Oksanen 2001).

Many concerns about mesocosm research reflect longstanding debates in ecology (Hurlbert 1984; Naeem 2001). Marine ecologists have long accepted that even field studies capture only a small part of natural oceanic variability. In making necessary spatial, temporal, and taxonomic simplifications to field or lab studies, we draw boundaries around our systems just as surely as we must with mesocosms.

\section{Examples of successful marine mesocosm research}

Although mesocosms have been under-used in marine ecology, marine researchers have demonstrated their utility. Below are examples of how marine mesocosms have addressed questions related to ecological processes, the fate and toxicity of environmental contaminants and eDNA - questions that can be intractable using laboratory experiments or field observations alone.

Marine mesocosm experiments perform as ideal platforms for conducting ecological research with small 
larvae or propagules of marine organisms, including observing larval growth and survival in real-time (Davis et al. 1996) and the evolution of aquatic organisms. In a recent study, Scheinin et al. (2015) measured evolutionary trends against $\mathrm{CO}_{2}$ enrichment that mimics future environmental change conditions. Marine mesocosms have also been used to validate the effectiveness of different seeding techniques on genetic diversity before conducting restoration efforts in the field (Ort et al. 2014).

Such systems can also be ideal for validating the fate and impact of contaminants over longer timescales or that were observed in a laboratory and/or suggested by a model. For example, to measure the rate of ecosystem recovery from polluted sediments, Oviatt et al. (1984) used fourteen cylindrical mesocosms, $1.8 \mathrm{~m}$ in diameter and $5.5 \mathrm{~m}$ in depth, that were scaled to a natural system in terms of sunlight, temperature, tidal mixing and flushing, and mimicked the behavior of the natural system with regard to phytoplankton, zooplankton, benthos, metabolism, and nutrient concentration. Vethaak et al. (1996) performed a long-term (3-year) study using large mesocosms $(40 \mathrm{~m} \times 40 \mathrm{~m} \times 3 \mathrm{~m})$ to determine whether diseases in European flounder (Platichthys flesus) were directly related to pollution. The mesocosm made it possible to separate pollution from other potential causes of disease, such as perturbation due to climate change or non-native species. Their results demonstrated liver neoplasia (tumor formation) in fish under simulated conditions with environmentally relevant levels of pollutants.

Marine mesocosm research at California's Monterey Bay Aquarium developed and calibrated eDNA techniques to detect mitochondrial DNA of bony fish and identify individuals to the family- or genus-level (Kelly et al. 2014). This approach could improve the cost, efficiency, and sensitivity of current marine monitoring programs. Mesocosm-based research also allowed scientists to test different techniques to quantify the number of target DNA copies, showing droplet digital polymerase chain reaction (PCR) had higher accuracy than quantitative PCR, especially at low eDNA concentrations (Doi et al. 2015). By moving beyond taxonomic identification, such techniques may allow estimation of the abundance and biomass of aquatic species with eDNA methods in the field. A recent study applied this approach to characterize patterns of eukaryotic diversity on oyster reefs in Virginia and Florida (Leray and Knowlton 2015).

\section{The future of mesocosms}

We contend that continued and increased use of mesocosm infrastructure can help answer complex questions in a changing world. The B2 Ocean is an example of a unique, large-scale, multi-purpose, marine mesocosm that supported fundamental advances in our understanding of ocean acidification by measuring coral reef community responses to changes in $\mathrm{pH}$ (Langdon et al. 2000, 2003). Although currently being redeveloped as a community platform for marine research (Panel 1), the B2 Ocean will become available for use for a variety of experiments and by a diversity of researchers.

In addition to scientific limitations, the cost and complexity of building large mesocosms are another reason that so few of these systems - either terrestrial or marine - are active. We cannot take full advantage of mesocosm research opportunities when such infrastructure is under-supported. However, by incorporating substantial public outreach efforts into new projects, both the public and scientific mission may benefit. By opening facilities to members of the public and educational groups, fees from visitors can help defray costs associated with research and maintenance. Incorporating projects in which the public can participate (eg citizen science) or learn provides additional data and supports "broader impacts" programs that are part of the mission of public and private foundations, many of which can and do serve as critical sources of funding.

We argue that marine mesocosms have a central role to play in advancing marine science and (potentially) public understanding. By providing a central stage around which diverse researchers can organize, mesocosms offer a platform for developing collaborative approaches and resolving complex ecological questions. The opportunities offered by mesocosms suggest that there is abundant room for exploring their diverse promise in marine research.

\section{Acknowledgements}

C Baxter, K Caldeira, and R Albright provided valuable input into earlier versions of this manuscript.

\section{References}

Álvarez-Romero JG, Pressey RL, Ban NC, et al. 2011. Integrated land-sea conservation planning: the missing links. Annu Rev Ecol Evol S 42: 381-409.

Atkinson MJ, Barnett H, Aceves H, et al. 1999. The Biosphere 2 coral reef biome. Ecol Eng 13: 147-71.

Biber E. 2011. The problem of environmental monitoring. U Colorado Law Rev 83: 1-82.

Brusca RC (Ed). 2010. The Gulf of California: biodiversity and conservation. Tucson, AZ: University of Arizona Press.

Cleary DF, Fauvelot C, Genner MJ, et al. 2006. Parallel responses of species and genetic diversity to El Nino-Southern Oscillation-induced environmental destruction. Ecol Lett 9: 304-10.

Cowen RK and Sponaugle S. 2009. Larval dispersal and marine population connectivity. Ann Rev Mar Sci 1: 443-66.

Davis M, Hodgkins GA, and Stoner AW. 1996. A mesocosm system for ecological research with marine invertebrate larvae. Mar Ecol-Prog Ser 130: 97-104.

Denny MW. 1993. Air and water: the biology and physics of life's media. Vol 341. Princeton, NJ: Princeton University Press. 
Doi H, Uchii K, Takahara T, et al. 2015. Use of droplet digital PCR for estimation of fish abundance and biomass in environmental DNA surveys. PLoS ONE 10: e0122763.

Falter JL, Atkinson MJ, and Langdon C. 2001. Production-respiration relationships at different timescales within the Biosphere 2 coral reef biome. Limnol Oceanogr 46: 1653-60.

Foote AD, Thomsen PF, Sveegaard S, et al. 2012. Investigating the potential use of environmental DNA (eDNA) for genetic monitoring of marine mammals. PLoS ONE 7: e41781.

Hurlbert SH. 1984. Pseudoreplication and the design of ecological field experiments. Ecol Monogr 54: 187-211.

Huxman TE, Troch PA, Chorover J, et al. 2009. The hills are alive: Earth science in a controlled environment. EOS T Am Geophys Un 90: 120.

Kelly RP, Port JA, Yamahara KM, and Crowder LB. 2014. Using environmental DNA to census marine fishes in a large mesocosm. PLoS ONE 9: e86175.

Kostylev VE, Erlandsson J, Ming MY, and Williams GA. 2005. The relative importance of habitat complexity and surface area in assessing biodiversity: fractal application on rocky shores. Ecol Complex 2: 272-86.

Langdon C, Broecker WS, Hammond DE, et al. 2003. Effect of elevated $\mathrm{CO}_{2}$ on the community metabolism of an experimental coral reef. Global Biogeochem Cy 17; doi:10.1029/2002 GB001941.

Langdon C, Takahashi T, Sweeney C, et al. 2000. Effect of calcium carbonate saturation state on the calcification rate of an experimental coral reef. Global Biogeochem Cy 14: 639_ 54.

Law KL, Morét-Ferguson S, Maximenko NA, et al. 2010. Plastic accumulation in the North Atlantic Subtropical Gyre. Science 329: $1185-88$.

Leray M and Knowlton N. 2015. DNA barcoding and metabarcoding of standardized samples reveal patterns of marine benthic diversity. P Natl Acad Sci USA 112: 2076-81.

Mann K and Lazier J. 2006. Dynamics of marine ecosystems: biological-physical interactions in the oceans (3rd edn). Malden, MA: Wiley-Blackwell.

Marino BDV and Odum HT (Eds). 1999. Biosphere 2: research past and present. Ecol Eng 13: 1-374.

Marubini F, Barnett H, Langdon C, and Atkinson MJ. 2001. Dependence of calcification on light and carbonate ion concentration for the hermatypic coral Porites compressa. Mar EcolProg Ser 220: 153-62.

Menge BA, Berlow EL, Blanchette CA, et al. 1994. The keystone species concept: variation in interaction strength in a rocky intertidal habitat. Ecol Monogr 64: 249-86.

Menge BA, Sanford E, Daley BA, et al. 2002. Inter-hemispheric comparison of bottom-up effects on community structure insights revealed using the comparative-experimental approach. Ecol Res 17: 1-16.

Naeem S. 2001. Experimental validity and ecological scale as criteria for evaluating research programs. In: Gardner RH, Kemp WM, Kennedy VS, and Petersen JE (Eds). Scaling relations in experimental ecology. New York, NY: Columbia University Press.

Oksanen L. 2001. Logic of experiments in ecology: is pseudoreplication a pseudoissue? Oikos 94: 27-38.

Ort BS, Cohen CS, Boyer KE, et al. 2014. Conservation of eelgrass (Zostera marina) genetic diversity in a mesocosm-based restoration experiment. PLoS ONE 9: e89316.

Osmond B, Ananyev G, Berry J, et al. 2004. Changing the way we think about global change research: scaling up in experimental ecosystem science. Glob Change Biol 10: 393-407.

Oviatt CA, Pilson MEQ, Nixon SW, et al. 1984. Recovery of a polluted estuarine system - a mesocosm experiment. Mar EcolProg Ser 16: 203-17.
Paine RT. 2010. Macroecology: does it ignore or can it encourage further ecological syntheses based on spatially local experimental manipulations? Am Nat 176: 385-93.

Pangle LA, DeLong SB, Abramson N, et al. 2015. The Landscape Evolution Observatory: a large-scale controllable infrastructure to study coupled Earth-surface processes. Geomorphology 244; doi:10.1016/j.geomorph.2015.01.020.

Pfister CA, Esbaugh AJ, Frieder CA, et al. 2014. Detecting the unexpected: a research framework for ocean acidification. Environ Sci Technol 48: 9982-94.

Pickett STA, Jones CG, and Kolasa J. 2007. Ecological understanding: the nature of theory and the theory of nature. Amsterdam, the Netherlands; Boston, MA: Elsevier/Academic Press.

Poynter J. 2006. The human experiment: two years and 20 minutes inside Biosphere 2. New York, NY: Thunder's Mouth Press.

Reider R. 2009. Dreaming the biosphere: the theater of all possibilities. Albuquerque, NM: University of New Mexico Press.

Sagarin R and Pauchard A. 2012. Observation and ecology: broadening the scope of science to understand a complex world. Washington, DC: Island Press.

Sagarin RD, Gilly WF, Baxter CH, et al. 2008. Remembering the Gulf: changes to the marine communities of the Sea of Cortez since the Steinbeck and Ricketts expedition of 1940. Front Ecol Environ 6: 374-81.

Scheinin M, Riebesell U, Rynearson TA, et al. 2015. Experimental evolution gone wild. J R Soc Interface 12; doi:10.1098/ rsif.2015.0056.

Schindler DW. 1998. Whole-ecosystem experiments - replication versus realism: the need for ecosystem-scale experiments. Ecosystems 1: 323-34.

Selkoe K, Scribner KT, and Galindo HM. 2015. Waterscape genetics - applications of landscape genetics to rivers, lakes, and seas. In: Balkenhol N, Cushman S, Storfer AT, and Waits LP (Eds). Landscape genetics: concepts, methods, applications. Hoboken, NJ: John Wiley \& Sons.

Siegel DA, Kinlan BP, Gaylord B, and Gaines SD. 2003. Lagrangian descriptions of marine larval dispersion. Mar Ecol-Prog Ser 260: $83-96$.

Strathmann RR. 1990. Why life histories evolve differently in the sea. Am Zool 30: 197-207.

Sweeney C. 1999. The diel carbon cycle of the Biosphere 2 Ocean. Ecol Eng 13: 235-47.

Teuten EL, Saquing JM, Knappe DRU, et al. 2009. Transport and release of chemicals from plastics to the environment and to wildlife. Philos T Roy Soc B 364: 2027-45.

Thomsen PF, Kielgast J, Iversen L, et al. 2012. Detection of a diverse marine fish fauna using environmental DNA from seawater samples. PLoS ONE 7: e41732.

Treml EA, Roberts J, Halpin PN, et al. 2015. The emergent geography of biophysical dispersal barriers across the Indo-West Pacific. Divers Distrib 21: 465-76.

Tyre AJ, Tenhumberg B, Field SA, et al. 2003. Improving precision and reducing bias in biological surveys: estimating falsenegative error rates. Ecol Appl 13: 1790-801.

Vellend M. 2005. Species diversity and genetic diversity: parallel processes and correlated patterns. Am Nat 166: 199-215.

Vethaak AD, Jol JG, Meijboom A, et al. 1996. Skin and liver diseases induced in flounder (Platichthys flesus) after long-term exposure to contaminated sediments in large-scale mesocosms. Environ Health Perspect 104: 1218-29.

Vitousek PM. 2004. Nutrient cycling and limitation: Hawai'i as a model system. New York, NY: Princeton University Press.

Watson JR, Hays CG, Raimondi PT, et al. 2011. Currents connecting communities: nearshore community similarity and ocean circulation. Ecology 92: 1193-200. 
Wilson C, Caughlin TT, Civitello DJ, and Flory SL. 2015. Combining mesocosm and field experiments to predict invasive plant performance: a hierarchical Bayesian approach. Ecology 96: 1084-92.

Witze A. 2015. US ocean sciences told to steer a new course. Nature 517: 538-39.

Wynn RB, Huvenne VAI, Le Bas TP, et al. 2014. Autonomous Underwater Vehicles (AUVs): their past, present and future contributions to the advancement of marine geoscience. Mar Geol 352: 451-68.
${ }^{6}$ Hopkins Marine Station, Stanford University, Pacific Grove, CA; ${ }^{7}$ PANGAS Science Coordination, Comunidad y Biodiversidad AC, Sonora, Mexico; ${ }^{8}$ Aquatic Health Program, School of Veterinary Medicine, University of California-Davis, Davis, CA; ${ }^{9}$ Honors College, University of Arizona, Tucson, AZ; ${ }^{10}$ Department of Hydrology and Water Resources, University of Arizona, Tucson, AZ**(patroch@email.arizona.edu)

\section{In Memoriam: Raphael (Rafe) Sagarin}

Rafe Sagarin - eminent marine biologist, friend, father, husband, brother, and son - lost his life to a drunken driver while riding his bicycle near Biosphere 2 in Oracle, AZ, on 28 May 2015. Rafe, an Associate Research Scientist at Biosphere 2, was an amazing individual whose intellect and caring attitude inspired others. One of his greatest gifts was translating science to the general public - something few of us do very well. With infectious enthusiasm for all that he did, Rafe was deeply passionate about the oceans, particularly the Sea of Cortez (Gulf

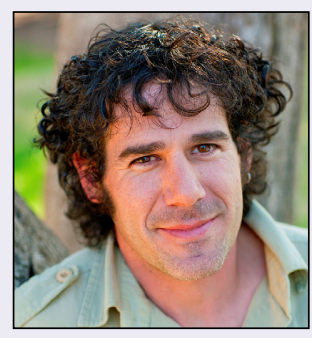
of California). The real world was his laboratory. He made connections where no one else would and, by applying an open mind and a creativity that had little patience for boundaries separating academic disciplines, he formed a rare bridge between academic and non-academic sectors. He strongly believed that holistic approaches could transcend barriers (between science and art, society and nature, observation and experimentalism) and that such approaches were key to resolving the scientific and societal challenges that we face. 